\title{
Chronic kidney disease, heart failure and anemia
}

\author{
Sean A Virani MSc MD FRCPC, Amit Khosla, Adeera Levin MD FRCPC
}

\author{
SA Virani, A Khosla, A Levin. Chronic kidney disease, heart \\ failure and anemia. Can J Cardiol 2008;24(Suppl B):22B-24B.
}

The triad of chronic kidney disease, heart failure and anemia is well described and frequently encountered in clinical practice. While individually these disease states are associated with significant morbidity and mortality, the presence of the triad portends an even worse prognosis. Anemia is prevalent among cohorts of patients with chronic kidney disease and heart failure, indicating that its presence may serve as a central unifying hypothesis to explain poor outcomes in these populations. Observational and interventional trials of erythropoietin-stimulating agents, however, have had variable results on cardiovascular end points. Data are now emerging that suggest that treating erythropoietin deficiency in and of itself may be as or more important than the absolute levels of hemoglobin attained. Future research in this arena must focus on the optimal dose of erythropoietin administered to hemoglobin level achieved that will result in improved cardiovascular outcomes for patients with heart failure and kidney disease.

Key Words: Anemia; Chronic kidney disease; EPO; Heart failure

\section{Maladie rénale chronique, insuffisance cardiaque et anémie}

La triade "maladie rénale chronique, insuffisance cardiaque et anémie » est bien connue et s'observe souvent en clinique. La présence de l'un ou l'autre de ces états pathologiques est associée à une morbidité et à une mortalité importantes, mais la présence concomitante des trois comporte un pronostic encore plus sombre que leur présence isolée. L'anémie est fréquente chez les patients atteints d'une maladie rénale chronique et d'insuffisance cardiaque; sa présence pourrait donc servir d'hypothèse unificatrice centrale pour expliquer les résultats médiocres, constatés chez ces patients. Des études observationnelles et interventionnelles sur des stimulants érythropoiétiques ont toutefois donné des résultats variables sur des événements cibles cardiovasculaires. Cependant, d'après de nouvelles données, le traitement du déficit en érythropoḯtine pourrait être aussi important, sinon plus, que le taux absolu atteint d'hémoglobine. La recherche dans le domaine doit porter tout particulièrement sur la dose optimale d'érythropoïétine qui, administrée au taux atteint d'hémoglobine, permettra d'améliorer les résultats cardiovasculaires observés chez les patients souffrant d'insuffisance cardiaque et d'une maladie rénale.
$\mathrm{T}$ he importance of understanding physiology, pathophysiology and treatment options in complex conditions cannot be overstated. In the context of heart failure (HF), the combination of kidney disease, anemia and cardiovascular disease leads to poor clinical outcomes. Despite the knowledge of the common association of these conditions and their frequency, robust evidence as to the best treatment regimens for the triad is lacking.

The present review is intended to describe the complex relationship that exists between chronic kidney disease (CKD), cardiovascular disease (CVD) and anemia. In particular, the potential role for anemia as both contributor to and an effect of HF is explored.

\section{THE CARDIO-RENAL-ANEMIA SYNDROME}

Decline in glomerular filtration rate (GFR) is associated with a stepwise increase in all-cause mortality at all levels of kidney function (1). The vast majority of individuals with CKD will experience death due to cardiovascular causes rather than progress to end-stage renal disease or dialysis (2). The high burden of CVD in CKD cohorts, and vice versa, is a reflection of the fact that both disease processes share similar risk factors. Having one disease increases an individual's risk of having the other; the combination of both is associated with a higher mortality than either disease alone (3-5). This observation is consistent across a number of studies including subgroup analyses from the Antihypertensive and Lipid-Lowering Treatment to Prevent Heart Attack Trial (ALLHAT) (6). CV end points, including myocardial infarction, stroke, need for revascularization, the presence of coronary artery disease and all forms of atherosclerotic vascular disease, were increased in study participants as GFR decreased.

The presence or absence of anemia appears to add another layer of complexity to the relationship between CKD and CVD. Among individuals with CKD, at all levels of GFR, anemia portends a poor prognosis and is associated with increased mortality compared with those individuals with preserved hemoglobin ( $\mathrm{Hgb}$ ) (7). Cardiovascular outcomes across a variety of cardiac disease states are similarly worse in the presence of anemia. Potential hypotheses for this association suggest that: anemia is a marker of cardiac function/dysfunction due to the presence of inflammatory cytokines; anemia is a reflection of the metabolic milieu and occurs in the presence of other traditional and nontraditional risk factors for cardiac disease; anemia reduces oxygen carrying capacity and results in myocardial ischemia; and anemia contributes to maladaptive cardiac remodelling.

Anemia is common in HF patients; the prevalence of anemia increases with severity of New York Heart Association functional classification $(8,9)$. In reviewing a series of recently published major HF trials, anemia occurred in $9 \%$ to $25 \%$ of patients $(5,10-12)$. The presence of anemia in this patient population is associated with recurrent hospitalization and reduced survival (13). Absolute Hgb levels correlate with one-year survival (10) and an increase in mortality is observed when Hgb levels fall below $120 \mathrm{~g} / \mathrm{L}$; this relationship of poor outcomes and $\mathrm{Hgb}$ values less than $120 \mathrm{~g} / \mathrm{L}$ is consistent across a variety of observational studies.

\section{THE ROLE OF ERYTHROPOIETIN- STIMULATING AGENTS}

Epidemiological and observational data suggest that Hgb levels are an important determinant of outcomes in patients with CKD and CVD. Anemia is associated with CKD progression, an increased risk of developing CVD and decreased survival. Older observational studies, before the routine administration of erythropoietin-stimulating agents

Division of Cardiology, Division of Nephrology, University of British Columbia, Vancouver, British Columbia

Correspondence: Dr Sean Virani, Division of Cardiology, University of British Columbia, 9th Floor, 2775 Laurel Street, Vancouver, British Columbia

V5Z 1M9. Telephone 604-875-5092,fax 604-875-5761,e-mail svirani@telus.net Eु alevin@providencehealth.bc.ca

Received for publication December 21, 2007. Accepted April 19, 2008 
(ESA), suggested that higher Hgb levels were associated with better outcomes, including a survival advantage; these were, however, observational cohort studies and thus limited in interpretation due to the inherent nature of that study design. It remained unclear, on the basis of early trials, whether normalization of $\mathrm{Hgb}$ was associated with improved outcomes and more specifically, what level of Hgb should be targeted in at risk populations.

Of note is the fact that anemia is not present in all individuals with reduced GFR. There is significant heterogeneity in $\mathrm{Hgb}$ levels at each stage of kidney disease (14). Thus, it is possible that anemia reflects not only reduced GFR but other clinical states such as inflammation (15). Similarly, while anemia can exist in the context of HF due to a number of factors including dilution, inflammation and chronic illness, it is not uniformly present. The additive problem of reduced kidney function in the context of HF may increase the propensity of an individual to become or stay anemic. This has not been well studied.

Additionally, there are a number of nonhematological effects of erythropoietin (15-18). As such, erythropoietin deficiency or resistance itself may be detrimental, irrespective of Hgb levels per se. In as much as erythropoietin has antiapoptotic and anti-inflammatory effects, and mediates neovascularization, there may be advantages to repleting or supplementing the hormone in those with demonstrated deficiencies, most commonly heralded by the presence of anemia. Conversely, stimulation of vascular erythropoietin receptors may produce hypertension independent of increased viscosity (15).

It remains unclear as to what the net balance of these positive and negative effects of erythropoietin are in the context of various disease states. It is likely, however, that the effects of anemia on CKD progression, CVD and survival are mediated through both low $\mathrm{Hgb}$ and low erythropoietin levels, in addition to the variety of complex processes that regulate this interaction, and the primary disease processes of kidney and cardiovascular disease per se.

\section{TRIALS OF HGB NORMALIZATION AND CARDIOVASCULAR OUTCOMES}

Small studies have suggested that partial correction of anemia with ESA, among hemodialysis patients, is associated with improvements in blood pressure and pulse pressure (19). However, on balance, among randomized controlled trials of dialysis patients, there has been no demonstration of an impact of normalization of $\mathrm{Hgb}$ with ESA on CVD events or survival (20-25); moreover, many of these studies have raised questions of harm (vascular access thrombosis and stroke), which have not been definitively addressed. Smaller randomized trials among nondialysis patients have also failed to show improvements in surrogate end points for CV outcomes (left ventricular mass index on echocardiography and decline in GFR) among ESA-treated patients (26-29)

Recent larger randomized clinical trials have had variable and somewhat conflicting results. The Cardiovascular Risk Reduction by Early Anemia Treatment with Epoetin beta (CREATE) trial (30) failed to demonstrate a difference in CV events among CKD patients randomly assigned to high and low Hgb arms, although the trial was not powered for the relatively low event rate. Importantly, there was no difference in the number of adverse events between treatment groups. In contrast, the Correction of Hemoglobin and Outcomes in Renal Insufficiency (CHOIR) trial (31), which randomly assigned approximately 1400 patients to high and normal Hgb arms, was terminated early due to unlikelihood of significant difference and suggestion of harm in the high $\mathrm{Hgb}$ arm. These findings are problematic and have formed the basis of much controversy for a number of reasons: the significance of the outcomes varies when adjusted for differences in the baseline cardiovascular risk between the two groups, and there was significant drop out of the original cohort.

Both of these trials, in addition to two recently performed metaanalyses $(32,33)$, have highlighted the importance of erythropoietin dosing and its relation to the target $\mathrm{Hgb}$ achieved. Higher erythropoietin doses may be associated with worse CV outcomes in CKD patients, tipping the balance between the hormone's positive and negative effects. The critical amount of erythropoietin relative to $\mathrm{Hgb}$ achieved that may be detrimental has yet to be elucidated. These findings have given light to the question of whether ESA dose is as or more important than Hgb level achieved and whether responsiveness to erythropoietin may be a marker of survival in this patient population. Most recently, an analysis comparing the ratios of ESA dose to Hgb level achieved (A Levin, Division of Nephrology, University of British Columbia; personal communication) has suggested that ESA dose rather than Hgb achieved predicts outcomes; high dose ESA being more 'toxic' in a sick population of CKD patients with pre-existing CVD.

While there may be a complex interaction between erythropoietin dose and $\mathrm{Hgb}$ in relation to CV outcomes, it is unknown based on the current literature whether specific subpopulations exist that would benefit from higher Hgb levels, most specifically individuals with HF.

\section{HF AND ANEMIA}

$\mathrm{HF}$ is associated with reduced kidney function and anemia. The presence of either or both portends worse outcomes (3,5,34-36). Intervention trials of $\mathrm{Hgb}$ normalization among $\mathrm{HF}$ patients have been few and caution should be given to the generalizability of their results based on the small numbers of patients recruited. Nonetheless, relatively high-dose erythropoietin administration in selected cohorts has been shown to improve soft clinical end points, including New York Heart Association functional classification, oxygen consumption, B-type natriuretic peptide levels and recurrent hospitalization (37-40). Most importantly, significant differences in adverse events related to erythropoietin administration were not noted among study patients.

Clarity regarding the specific impact of ESA in HF is limited by the ubiquitous presence of reduced kidney function in this patient population. Furthermore, it is uncertain, based on the limited available data, whether the demonstrated benefits of ESA in HF patients is due to correction of anemia, treatment of erythropoietin deficiency or prevention of further deterioration in renal function.

\section{FUTURE CONSIDERATIONS}

It is clear, based on the current body of literature, that anemia is associated with poorer outcomes in patients with CVD and CKD, and that in turn, CVD and CKD are tightly coupled. Erythropoietin has pleotropic effects that may be beneficial in these disease states, but its vasoactive effects may be potentially harmful at higher doses. The cycle of HF, anemia and reduced kidney function is well described. The future of research in this arena must focus on whether Hgb levels or erythropoietin deficiency, or some ratio of $\mathrm{Hgb} /$ erythropoietin dose should be the target for therapy. The presence of clinical equipoise should serve as fertile soil for further research questions and randomized clinical trials.

At the current time, 15 clinical trials are registered that examine anemia therapy in various HF populations (41). The clinical community interested in addressing the poor outcomes of those with CKD, HF or both, is increasingly focused on anemia as a perceived modifiable risk factor for poor outcomes. The complexity of the relationship among $\mathrm{CKD}, \mathrm{HF}$ and anemia requires ongoing study, and patience on the part of clinicians.

DISCLOSURE: Dr A Levin receives grants from Amgen, Ortho and Roche, and has received honoraria from all for lecture fees. Dr SA Virani and Dr A Khosla have no conflicts of interest to report.

\section{REFERENCES}

1. Go AS, Chertow GM, Fan D, McCulloch CE, Hsu CY. Chronic kidney disease and the risks of death, cardiovascular events, and hospitalization. N Engl J Med 2004;351:1296-305.

2. Canadian Organ Replacement Register Annual Data Report (2007). <http://secure.cihi.ca/cihiweb/dispPage.jsp?cw page $=$ services_corr_e $>$ (Version current at May 22, 2008). 
3. Go AS, Yang J, Ackerson LM, et al. Hemoglobin level, chronic kidney disease, and the risks of death and hospitalization in adults with chronic heart failure: the Anemia in Chronic Heart Failure: Outcomes and Resource Utilization (ANCHOR) Study. Circulation 2006;113:2713-23.

4. Wali RK, Henrich WL. Chronic kidney disease: a risk factor for cardiovascular disease. Cardiol Clin 2005;23:343-62.

5. Al-Ahmad A, Rand WM, Manjunath G, et al. Reduced kidney function and anemia as risk factors for mortality in patients with left ventricular dysfunction. J Am Coll Cardiol 2001;39:955-62.

6. Rahman M, Brown CD, Coresh J, et al. The prevalence of reduced glomerular filtration rate in older hypertensive patients and its association with cardiovascular disease: A report from the Antihypertensive and Lipid-Lowering Treatment to Prevent Heart Attack Trial. Arch Intern Med 2004;164:969-76.

7. Astor BC, Coresh J, Heiss G, Pettitt D, Sarnak MJ. Kidney function and anemia as risk factors for coronary heart disease and mortality: The Atherosclerosis Risk in Communities (ARIC) Study. Am Heart J 2006;151:492-500.

8. Androne AS, Katz SD, Lund L, et al. Hemodilution is common in patients with advanced heart failure. Circulation 2003;107:226-9.

9. Anand I, McMurray J, Whitmore J, et al. Anemia and Its Relationship to Clinical Outcome in Heart Failure. Circulation 2004;110:149-54

10. Horwich TB, Fonarow GC, Hamilton MA, et al. Anemia is associated with worse symptoms, greater impairment in functional capacity and a significant increase in mortality in patients with advanced heart failure. J Am Coll Cardiol 2002;39:1780-6.

11. Sharma R, Francis D, Pitt B, et al. Hemoglobin predicts survival in patients with chronic heart failure: A sub-study of the ELITE II trial. Eur Heart J 2004;25:1021-8.

12. Anand IS, Kuskowski MA, Rector TS, et al. Anemia and change in hemoglobin over time related to mortality and morbidity in patients with chronic heart failure: Results from Val-HeFT. Circulation 2005;112:1121-7.

13. Ezekowitz JA, McAlister FA, Armstrong PW. Anemia is common in heart failure and is associated with poor outcomes. Circulation 2003;107:223-5.

14. Levin A, Djurdjev O, Duncan J, et al. Haemoglobin at time of referral prior to dialysis predicts survival: An association of haemoglobin with long-term outcomes. Nephrol Dial Transplant 2006;21:307-12.

15. Ksiazek A, Zaluska WT, Ksiazek P. Effect of recombinant human erythropoietin on adrenergic activity in normotensive hemodialysis patients. Clin Nephrol 2001;56:104-9.

16. Ribatti D, Presta M, Vacca A, et al. Human erythropoietin induces a pro-angiogenic phenotype in cultured endothelial cells and stimulates neovascularization in vivo. Blood 1999;93:2627-36.

17. Westenfelder C, Biddle DL, Baranowski RL. Human, rat, and mouse kidney cells express functional erythropoietin receptors. Kidney Int 1999;55:808-20.

18. Parsa CJ, Matsumoto A, Kim J, et al. A novel protective effect of erythropoietin in the infarcted heart. J Clin Invest 2003;112:999-1007.

19. London GM, Pannier B, Guerin AP, et al. Alterations of left ventricular hypertrophy in and survival of patients receiving hemodialysis: Follow-up of an interventional study. J Am Soc Nephrol 2001;12:2759-67.

20. Besarab A, Bolton WK, Browne JK, et al. The effects of normal as compared with low hematocrit values in patients with cardiac disease who are receiving hemodialysis and epoetin. N Eng J Med 1998;339:584-90.

21. Furuland $\mathrm{H}$, Linde $\mathrm{T}$, Ahlmen J, et al. A randomized controlled trial of haemoglobin normalization with epoetin alfa in pre-dialysis and dialysis patients. Nephrol Dial Transplant 2003;18:353-61.

22. Foley RN, Parfrey PS, Morgan J, et al. Effect of hemoglobin levels in hemodialysis patients with asymptomatic cardiomyopathy. Kidney Int 2000;58:1325-35.

23. Moreno F, Sanz-Guajardo D, López-Gómez JM, Jofre R, Valderrábano F. IIncreasing the hematocrit has a beneficial effect on quality of life and is safe in selected hemodialysis patients. Spanish Cooperative Renal Patients Quality of Life Study Group of the Spanish Society of Nephrology. J Am Soc Nephrol 2000;11:335-42.

24. McMahon LP, McKenna MJ, Sangkabutra T, et al. Physical performance and associated electrolyte changes after haemoglobin normalization: A comparative study in haemodialysis patients. Nephrol Dial Transplant 1999;14:1182-7.

25. Parfrey PS, Foley RN, Wittreich BH, et al. Double-blind comparison of full and partial anemia correction in incident hemodialysis patients without symptomatic heart disease. J Am Soc Nephrol 2005;16:2180-9.

26. Roger SD, McMahon LD, Clarkson A, et al. Effects of early and late intervention with epoetin alpha on left ventricular mass among patients with chronic kidney disease (stage 3 or 4): Results of a randomized clinical trial. J Am Soc Nephrol 2004; 15:148-56.

27. Levin A, Djurdjev O, Thompson C, et al. Canadian randomized trial of hemoglobin maintenance to prevent or delay left ventricular mass growth in patients with CKD. Am J Kidney Dis 2005;46:799-811.

28. Macdougall IC, Temple RM, Kwan JT. Is early treatment of anaemia with epoetin-alpha beneficial to pre-dialysis chronic kidney disease patients? Results of a multicentre, open-label, prospective, randomized, comparative group trial. Nephrol Dial Transplant 2007;22:784-93.

29. Ritz E, Laville M, Bilous RW, et al. Target level for hemoglobin correction in patients with diabetes and CKD: Primary results of the Anemia Correction in Diabetes (ACORD) Study. Am J Kidney Dis 2007;49:194-207.

30. Drueke TB, Locatelli F, Clyne N, et al. Normalization of hemoglobin level in patients with chronic kidney disease and anemia. N Engl J Med 2006;355:2071-82.

31. Singh AK, Szczech L, Kezhen LT, et al. Correction of anemia with epoetin alfa in chronic kidney disease. N Engl J Med 2006;355:2085-98

32. Levin A, Djurdjev O, Ravani P, Macdougall I, MacMahon L. Metaanalysis of individual patient data from randomized trials with epoetin alfa therapy: Progression of kidney disease. American Society of Nephrology Renal Week, San Francisco, California, 2007. (Conference presentation)

33. Phrommintikul A, Haas SJ, Elsik M, et al. Mortality and target hemoglobin concentrations in anaemic patients with chronic kidney disease treated with erythropoietin: A meta-analysis. Lancet 2007;369:381-8

34. Bansal N, Tighiouart MS, Weiner D, et al. Anemia as a risk factor for kidney function decline in individuals with heart failure. Am J Cardiology 2007;99:1137-42.

35. Mozaffarian D, Nye R, Levy WC. Anemia predicts mortality in severe heart failure. The Prospective Amlodipine Survival Evaluation (PRAISE). J Am Coll Cardiol 2003;41:1933-9.

36. Lindenfeld J. Prevalence of anemia and effects on mortality in patients with heart failure. Am Heart J 2005;149:391-401.

37. Palazzuoli A, Silverberg D, Iovine F, et al. Erythropoietin improves anemia, exercise tolerance and renal function, and reduces B-type natriuretic peptide and hospitalization in patients with heart failure and anemia. Am Heart J 2006;152:1096.e9-15.

38. Palazzuoli A, Silverberg D, Iovine F, et al. Effects of $\beta$-erythropoietin treatment on left ventricular remodeling, systolic function, and B-type natriuretic peptide levels in patients with the cardiorenal anemia syndrome. Am Heart J 2007;154:645.e9-e15.

39. Silverberg D, Wexler D, Sheps D, et al. The effect of correction of mild anemia in severe, resistant congestive heart failure using subcutaneous erythropoietin and intravenous iron: A randomized controlled study. J Am Coll Cardiol 2001;37:1775-80.

40. Mancini DM, Katz SD, Lang CC, et al. Effect of erythropoietin on exercise capacity in patients with moderate to severe chronic heart failure. Circulation 2003;107:294-299.

41. Clinical Trials. <www.clinicaltrials.gov $>$ (Version current at November 15, 2007). 